\title{
PERANAN PEREMPUAN DALAM USAHA PENGOLAHAN IKAN CAKALANG (Katsuwonus pelamis L) ASAP DI KELURAHAN GIRIAN ATAS KECAMATAN GIRIAN KOTA BITUNG PROVINSI SULAWESI UTARA
}

\author{
Daniel Tempomona'; Djuwita R.R. Aling2; Christian R. Dien² \\ 1) Mahasiswa Fakultas Perikanan dan IImu Kelautan Universitas Sam Ratulangi, Manado. \\ 2) Staff Pengajar Fakultas Perikanan dan Ilmu Kelautan Universitas Sam Ratulangi, Manado. \\ Koresponden email: magheltakalamingan08@gmail.com
}

\begin{abstract}
Bitung City becomes a very potential area to be developed capture fishery business, on the basis of that also Bitung City known as Cakalang City. The large potential of skipjack fish resources in Bitung City caused the high interest of the community to process the fish, one of which is the cakalang tuna fish or the local language known as cakalang fufu. The purpose of this research is to know the condition of the group of smoked cakalang fish processing business. To know what is the role of woman in cakalang smoke processing business in Girian Atas Village, Girian Subdistrict, Bitung City, North Sulawesi Province. The benefits of this research is As a suggestion for the author to apply the knowledge that has been obtained during the lecture through research conducted directly in the field. The research place is located in Kampung Loyang, Rt 18, Neighborhood 06, Girian Atas Sub-District, Girian Sub-district, Bitung City, North Sulawesi Province. The study time is approximately 4 months starting from May 2017 until August 2017. Data collection techniques used in this study are Observation, Interview, and Purposive Sampling is the business group of skipjack fish in Girian Atas Village amounted to 16 women.

The results show that the cakalang tuna business in Kampung Loyang, Girian Atas village, Bitung City is still in the "home industry" stage or home industry. Women in the skipjack tuna business group have an important role, ranging from the process of availability of raw materials, the provision of equipment and materials processing, washing, cleavage, installation of bamboo (stapled), the process of curing up, and marketing of tuna fish, Women. Tuna fish processing process is done 20 times production in a month, in $1 \mathrm{x}$ production if fish raw material $80-200 \mathrm{Kg}$, labor required 2-4 people. If the fish as much as 100 tail after processing will be 200 flops. From the interview result, the work time of women in the tuna fish processing place for 3-4 hours amounted to 3 people, 5-6 hours amounted to 8 people and $>6$ totaled 5 people. Wages adjusted to the workforce in a day Rp. 100,000
\end{abstract}

Keywords: smoke fish, fish processing, skipjack tuna, woman roles

\begin{abstract}
Abstrak
Kota Bitung menjadi kawasan yang sangat potensi untuk dikembangkan usaha perikanan tangkap, atas dasar itu pula Kota Bitung dikenal sebagai Kota Cakalang. Besarnya potensi sumberdaya ikan cakalang di Kota Bitung menyebabkan tingginya minat masyarakat untuk mengolah ikan, salah satunya pegolahan ikan cakalang asap atau yang dalam bahasa lokalnya dikenal dengan istilah cakalang fufu. Penelitian ini bertujuan Untuk mengetahui keadaan kelompok usaha pengolahan ikan cakalang asap, Untuk mengetahui apa saja peran perempuan dalam usaha pengolahan ikan cakalang asap di Kelurahan Girian Atas, Kecamatan Girian, Kota Bitung Provinsi Sulawesi Utara. Manfaat dari penelitian ini adalah Sebagai saran bagi penulis untuk menerapkan ilmu pengetahuan yang telah diperoleh selama kuliah melalui penelitian yang dilakukan langsung di lapangan. Tempat penelitian bertempat di Kampung Loyang, Rt 18, Lingkungan 06, Kelurahan Girian Atas, Kecamatan Girian, Kota Bitung, Provinsi Sulawesi Utara. Waktu penelitian kurang lebih 4 bulan yaitu dimulai dari bulan Mei 2017 sampai dengan bulan Agustus 2017. Teknik pengumpulan data digunakan dalam penelitian ini adalah Observasi, Wawancara, dan Purposive Sampling yaitu kelompok usaha ikan cakalang asap di Kelurahan Girian Atas berjumlah 16 orang perempuan.

Hasil menunjukan bahwa Usaha ikan cakalang asap di Kampung Loyang, Kelurahan Girian Atas, Kota Bitung masih dalam tahap "home industry" atau industri rumah tangga. Perempuan dalam kelompok usaha pengolahan ikan cakalang asap mempunyai peranan penting, mulai dari proses ketersediaan bahan baku, penyediaan peralatan dan bahan pengolahan, pencucian, pembelahan, pemasangan pada bambu (dijepit), proses pengasapan sampai, dan pemasaran hasil pengolahan ikan cakalang asap, melibatkan peran perempuan. Proses pengolahan ikan cakalang asap dilakukan 20 kali produksi dalam sebulan, dalam 1 x produksi apabila bahan baku ikan $80-200 \mathrm{Kg}$, tenaga kerja yang dibutuhkan 2-4 orang. Apabila ikan sebanyak 100 ekor setelah diolah akan menjadi 200 jepit. Dari hasil wawancara, curahan waktu kerja perempuan di tempat pengolahan ikan cakalang asap 3-4 jam berjumlah 3 orang, $5-6$ jam berjumlah 8 orang dan $>6$ berjumlah 5 orang. Pengupahan disesuaikan dengan tenaga kerja dalam sehari Rp. 100.000
\end{abstract}

Kata kunci: ikan asap, pengolahan ikan, cakalang, peranan wanita 


\section{PENDAHULUAN}

Kota Bitung memiliki luas wilayah $31.350,35 \mathrm{Ha}$ atau $313 \mathrm{Km}^{2}$ dengan batas sebelah Utara yaitu Kepulauan Sangihe, batas sebelah Selatan Laut Maluku, batas Timur Laut Maluku dan Samudera Pasifik, dan batas sebelah Barat Kabupaten Minahasa Utara. Dalam keadaan letak wilayah ini, Kota Bitung merupakan salah satu kawasan pengembangan perikanan di Provinsi Sulawesi Utara. Lokasi ini memiliki infrastruktur yang mendukung usaha perikanan ikan cakalang asap dan pelabuhan perikanan samudra Bitung. Perkembangan industri perikanan di Kota Bitung diarahkan pada industri pengolahan perikanan laut, khususnya untuk peningkatan nilai tambah potensi beberapa jenis ikan ekonomis tinggi seperti cakalang, tuna, dan layang sehingga hasil yang diperoleh dari sektor perikanan sangat menjanjikan (Dinas Kelautan dan Perikanan Kota Bitung, 2015).

Kota Bitung menjadi kawasan yang sangat potensi untuk dikembangkan usaha perikanan tangkap, atas dasar itu pula Kota Bitung dikenal sebagai Kota Cakalang. Besarnya potensi sumberdaya ikan cakalang di Kota Bitung menyebabkan tingginya minat masyarakat untuk mengolah ikan, salah satunya pegolahan ikan cakalang asap atau yang dalam bahasa lokalnya dikenal dengan istilah cakalang fufu. Kota Bitung terdiri dari 8 kecamatan dan 69 kelurahan, salah satunya kelurahan girian atas, beberapa masyarakatnya memiliki pekerjaan yaitu berwirausaha. Kegiatan usahanya adalah memproduksi ikan cakalang asap usaha ini dilakukan untuk mengembangkan proses pengolahan ikan sehingga dapat menambah pendapatan daerah, memenuhi kebutuhan keluarga, dan menciptakan lapangan kerja tambahan bagi masyarakat sekitar (Dinas Kelautan dan Perikanan Kota Bitung, 2015).

Keberadaan usaha pengolahan ikan cakalang asap di Kota Bitung, selain memberikan kontribusi ekonomi dan mendorong investasi, juga menciptakan stuktur ekonomi yang kuat dan kokoh khususnya kontribusi terhadap perekonomian wilayah regional Kawasan Timur Indonesia. Usaha pengolahan ikan cakalang asap di Kota Bitung juga tidak lepas dari peran aktif kaum perempuan, potensi kaum perempuan sangat penting dalam kegiatan sosial ekonomi dan modal dasar dalam pembangunan. Untuk itu perlu mengetahui bagaimana Peranan perempuam dalam kelompok usaha pengolahan ikan cakalang asap yang dilakukan di Kelurahan Girian Atas.

\section{Perumusan Masalah}

1. Bagaimana keadaan kelompok usaha pengolahan Ikan Cakalang (Katsuwonus Pelamis) asap di Kelurahan Girian Atas, Kecamatan Girian Kota Bitung, Provinsi Sulawesi Utara.

2. Bagaimana peran perempuan dalam kelompok usaha pengolahan Ikan Cakalang (Katsuwonus Pelamis) asap di Kelurahan Girian Atas, Kecamatan Girian Kota Bitung, Provinsi Sulawesi Utara.

\section{Tujuan Penelitian}

1. Mengetahui keadaan kelompok usaha pengolahan Ikan Cakalang (Katsuwonus Pelamis) asap di Kelurahan Girian Atas, Kecamatan Girian, Kota Bitung, Provinsi Sulawesi Utara.

2. Mengetahui apa saja peran perempuan dalam usaha pengolahan ikan cakalang asap di Kelurahan 
Girian Atas, Kecamatan Girian, Kota Bitung Provinsi Sulawesi Utara.

\section{Manfaat Penelitian}

1. Sebagai sarana bagi penulis untuk menerapkan ilmu pengetahuan yang telah diperoleh selama kuliah melalui penelitian yang dilakukan langsung di lapangan.

2. Sebagai pustaka serta acuan dalam melakukan penelitian pada tempat yang sama dilain waktu.

3. Sebagai bahan informasi bagi instansi untuk mengetahui aktivitas peran perempuan dalam usaha pengolahan ikan cakalang asap di Kelurahan Girian Atas, Kecamatan Girian Kota Bitung Provinsi Sulawesi Utara.

\section{Tempat Penelitian}

Penelitian ini bertempat di Kampung Loyang RT 18 Lingkungan 06, Kelurahan Girian Atas, Kecamatan Girian, Kota Bitung, Provinsi Sulawesi Utara.

\section{Waktu Penelitian}

Waktu yang digunakan dalam pelaksanaan penelitian dimulai dari survei lokasi penelitian, konsultasi dan penyusunan rencana kerja penelitian, pengumpulan data, konsultasi laporan sampai pada ujian, kurang lebih 4 bulan yaitu dimulai dari bulan Mei 2017 sampai dengan bulan Agustus 2017.

\section{METODOLOGI PENELITIAN}

\section{Metode Penelitian}

Studi kasus termasuk dalam penelitian analisis deskriptif, yaitu penelitian yang dilakukan terfokus pada suatu kasus tertentu untuk diamati dan dianalisis secara cermat sampai tuntas. Kasus yang dimaksud bisa berupa tunggal atau jamak, misalnya berupa individu atau kelompok (Sutedi, 2009).

Data studi kasus dapat diperoleh dari semua pihak yang bersangkutan, dengan kata lain data dalam studi ini dikumpulkan dari berbagai sumber (Nawawi, 2003).

\section{Teknik Pengumpulan Data Observasi}

Metode observasi merupakan metode pengumpul data yang dilakukan dengan cara mengamati dan mencatat secara sistematik gejala-gejala yang diselidiki (Supardi, 2006).

\section{Wawancara}

Metode wawancara adalah proses tanya jawab dalam penelitian yang berlangsung secara lisan dimana dua orang atau lebih bertatap muka mendengarkan secara langsung informasi-informasi atau keteranganketerangan (Supardi, 2006).

\section{Purposive Sampling}

Sugiyono (2010), mengartikan (purposive sampling) adalah teknik untuk menentukan sampel penelitian dengan beberapa pertimbangan tertentu yang bertujuan agar data yang diperoleh nantinya bisa lebih representatif. Pertimbangan dalam hal ini adalah pekerja perempuan pengolahan ikan cakalang asap, dimana dari 19 orang tenaga kerja diambil secara sengaja 16 orang yang dipandang dapat mewakili populasi.

\section{Metode Analisis Data}

Analisis data hasil penelitian dibedakan dalam dua macam, yaitu analisis kuantitatif dan analisis kualitatif (Fathoni, 2006). Analisis kuantitatif merupakan pengolahan data dengan menggunakan perhitungan matematis 
sederhana seperti penjumlahan, pengurangan, perkalian, angka rata-rata dan sebagainya, yang meliputi analisis usaha aspek keuangan, sumberdaya manusia, operasi/produksi dan pemasaran. Sedangkan analisis kualitatif adalah pengolahan data yang dilakukan melalui pertimbangan-pertimbangan logika dengan bahasa-bahasa penulis yang sistematis. Data yang telah dianalisis kemudian diinterpretasikan sebagai hasil penelitian, yang meliputi wawancara, analisis dokumen, diskusi, atau observasi.

\section{HASIL DAN PEMBAHASAN}

Keadaan Umum Kelompok Ustafu (Usaha Tampa Fufu)

\section{Sejarah Kelompok Ustafu}

Dalam perkembangannya

individu - individu yang bergerak dibidang pengolahan Cakalang Fufu membentuk sebuah kelompok yang diberi nama Ustafu pada tanggal 10 November 1996 dan saat itu telah beranggotakan sebanyak 20 orang. Dari 20 orang anggota kelompok masingmasing memliki peran dan fungsi yang berbeda, sebanyak 14 orang bertindak sebagai produsen (yang membuat cakalang asap), 2 orang sebagai penyedia bahan baku, dan 4 orang lainnya bertindak sebagai distributor atau yang mendistribusikan ikan cakalang asap. Saat ini jumlah tenaga kerja kelompok Ustafu sebanyak 19 orang tenaga kerja, 3 orang pekerja laki-laki dan 16 orang pekerja perempuan. Kelompok yang diketuai oleh Marwiah Lahadji ini memiliki Visi, "Meningkatkan Kesejahteraan Anggota Kelompok". Visi ini kemudian dijabarkan dalam beberapa misi yaitu:

1. Menumbuhkan rasa kebersamaan dan solidaritas antar anggota kelompok;
2. Meningkatkan pendapatan anggota kelompok;

3. Menambah/membuka lapangan pekerjaan bagi masyarakat sekitar; dan

4. Menjalin kemitraan dengan lembaga/instansi yang terkait dengan kegiatan kelompok seperti Badan Pelaksana Penyuluhan, Dinas Kelautan dan Perikanan atau lembaga-lembaga seperti perusahaan-perusahaan penyedia bahan baku.

Kelompok Ustafu menjadi salah satu kelompok yang cukup dikenal di Kota Bitung. Pada Tahun 2010 kelompok Ustafu menjadi Juara Terbaik 2 tingkat Provinsi untuk kategori Usaha Kecil Menengah (UKM) Pengolahan di Provinsi Sulawesi Utara, dan pada Tahun 2012 kelompok ini berhasil menjadi Juarai 1 Lomba Usaha Kecil Pengolahan Hasil Perikanan Terbaik Tingkat Provinsi Sulawesi Utara. Kemajuan - kemajuan yang diperoleh oleh kelompok ini tentunya tidak lepas dari peran serta penyuluh - penyuluh perikanan yang ada di Kota Bitung selain tentunya didukung dengan adanya keinginan yang besar dari masingmasing anggota kelompok untuk lebih maju dan berkembang.

Guna meningkatkan solidaritas dan kekompakan dalam usaha, kelompok Ustafu sering melakukan kegiatan pertemuan kelompok yang rutin dilakukan setiap minggu sekali dan dilakukan secara bergiliran di rumah masing - masing anggota kelompok. Selain pertemuan rutin, terkadang juga dilakukan pertemuan yang sifatnya insidentil sesuai dengan kebutuhan kelompok yang tentunya didampingi oleh Penyuluh Perikanan yang ada. 


\section{Peranan Perempuan Dalam Usaha Pengolahan Ikan Perencanaan Produksi}

Tabel. Perencanaan Produksi

\begin{tabular}{|c|c|c|c|c|}
\hline \multirow{2}{*}{ No } & \multirow{2}{*}{ Perencanaan Produksi } & \multicolumn{2}{|c|}{ Pelaku } & \multirow{2}{*}{$\begin{array}{l}\text { Alokasi Waktu } \\
\text { (Jam/menit) }\end{array}$} \\
\hline & & $\hat{\sigma}$ & q & \\
\hline 1. & Membeli bahan baku ikan cakalang di Tempat Pelelangan Ikan (TPI) & & $\sqrt{ }$ & 4 \\
\hline 2. & $\begin{array}{l}\text { Penyediaan bak penampung ikan, bak tempat mencuci ikan, } \\
\text { Menyiapkan piasau sebaqai alat pemotong dan membela ikan }\end{array}$ & & $\sqrt{ }$ & 30 \\
\hline 3. & Menyiapkan penjepit dari bambu untuk mengait ikan & $\sqrt{ }$ & $\sqrt{ }$ & 1 \\
\hline 4. & $\begin{array}{l}\text { Menyediakan/membeli sabut kelapa sebagai bahan bakar } \\
\text { pengasapan ikan cakalang }\end{array}$ & & $\sqrt{ }$ & 2 \\
\hline 5. & $\begin{array}{l}\text { Proses pengolahan ikan: } \\
\text {-Pencucian ikan } \\
\text {-Pembelahan dan penjepitan ikan } \\
\text {-Pengasapan ikan }\end{array}$ & & $\begin{array}{l}\sqrt{ } \\
\sqrt{ } \\
\sqrt{ }\end{array}$ & $\begin{array}{l}1 \\
2 \\
2\end{array}$ \\
\hline 6. & Pengangkutan produk jadi dari tempat pengolahan ke mobil & $\sqrt{ }$ & $\sqrt{ }$ & 30 \\
\hline 7. & $\begin{array}{l}\text { Pemasaran hasil produk ikan cakalang asap ke Pasar Karombasan } \\
\text { dan Pasar Bersehati }\end{array}$ & & $\sqrt{ }$ & 3 \\
\hline
\end{tabular}

Sumber : Data Primer, 2017

Keterangan : $\widehat{\delta}=$ Lakik-laki

$q=$ Perempuan

Berdasarkan tabel perencanaan produksi, perempuan mempunyai peranan penting dalam produksi pengolahan ikan cakalang asap, peranan perempuan dapat dilihat dari tabel rencana produsi nomor 1-5 dan nomor 7 , sedangkan peran laki-laki dalam proses pengolahan ikan cakalang asap dapat dilihat dari nomor 3 , dan nomor 6 . Ini berarti perempuan lebih mendominasi kegiatan usaha pengolahan ikan cakalang asap di Kampung Loyang, Kecamatan Girian Atas, Kota Bitung.

\section{Sumberdaya Manusia}

Tenaga Kerja Kelompok Usaha Pengolahan Ikan Cakalang Asap

Tenaga kerja merupakan penduduk yang berada dalam usia kerja. Menurut UU No. 13 tahun 2003 Bab I pasal 1 ayat 2 disebutkan bahwa tenaga kerja adalah setiap orang yang mampu melakukan pekerjaan guna menghasilkan barang atau jasa baik untuk memenuhi kebutuhan sendiri, keluarga maupun untuk masyarakat.

Tenaga kerja merupakan faktor produksi yang perlu diperhitungkan dalam proses produksi dan dalam jumlah yang cukup. Jam kerja ditentukan dari jumlah orang yang bekerja dalam 1 hari untuk menyelesaikan semua proses produksi sampai menghasilkan produk berupa ikan asap yang siap jual.

Usaha ikan cakalang asap merupakan peluang bagi masyarakat sekitar untuk menambah pendapatan dalam pemenuhan kebutuhan hidup. Bagi sebagian perempuan Kelurahan Girian Atas, mereka menjadikan kegiatan pengolahan ikan asap ini sebagi pekerjaan sampingan. Jumlah tenaga kerja kelompok Ustafu di Kampung Loyang dapat dilihat pada tabel berikut. 
Tabel. Peran Tenaga Kerja Kelompok Ustafu

\begin{tabular}{|c|c|c|c|c|}
\hline \multirow{2}{*}{ No } & \multirow{2}{*}{ Uraian Kegiatan Pengolahan } & \multirow{2}{*}{$\begin{array}{l}\text { Jumlah Tenaga Kerja } \\
\text { (Orang) }\end{array}$} & \multicolumn{2}{|c|}{ Peranan } \\
\hline & & & $\sigma^{\lambda}$ & q \\
\hline 1. & Ketersediaan bahan baku ikan & 2 & & $\sqrt{ }$ \\
\hline 2. & $\begin{array}{l}\text { Menyiapkan alat dan bahan untuk } \\
\text { kegiatan pengolahan ikan }\end{array}$ & 2 & & $\sqrt{ }$ \\
\hline 3. & Pencucian ikan & 1 & & $\sqrt{ }$ \\
\hline 4. & Pembelahan ikan & 2 & $\sqrt{ }$ & $\sqrt{ }$ \\
\hline 5. & Penjepitan dengan bambu & 2 & & $\sqrt{ }$ \\
\hline 6. & Pengasapan ikan & 2 & & $\sqrt{ }$ \\
\hline 7. & Pengangkutan ikan cakalang asap & 2 & $\sqrt{ }$ & $\sqrt{ }$ \\
\hline 8. & Pemasaran ikan cakalang asap & 3 & & $\sqrt{ }$ \\
\hline & Jumlah & 16 & & \\
\hline
\end{tabular}

Sumber : Data Primer, 2017

Berdasarkan tabel di atas, Jumlah tenaga kerja pengolah ikan cakalang asap berjumlah 16 orang perempuan. Pembagian tugas sudah diatur oleh ketua kelompok, mulai dari membeli bahan baku di Tempat Pelelangan Ikan oleh 2 orang perempuan Pengolahan 11 orang,
Pemasaran hasil produksi ikan cakalang asap 3 orang.

Apabilah dalam sehari, kelompok Ustafu ini memproduksi bahan baku ikan biasannya tenaga kerja yang dibutuhkan 3-4 orang. Jumlah tenaga kerja sekali produksi dalam sehari dapat dilihat pada tabel berikut.

Tabel. Jumlah Tenaga Kerja Satu Kali Produksi dalam Sehari

\begin{tabular}{|c|c|c|c|c|c|}
\hline No & Responden & Jenis Kelamin & $\begin{array}{c}\text { Bahan Baku lkan } \\
\text { (Per Kg) }\end{array}$ & $\begin{array}{c}\text { Jumlah Proses } \\
\text { Pengolahan } \\
\text { (Per Hari) }\end{array}$ & $\begin{array}{c}\text { Jumlah Tenaga } \\
\text { Kerja (Orang) }\end{array}$ \\
\hline 1. & Habira Hasan & $P$ & 100 & 1 & 3 \\
\hline 2. & Sarci Usman & $P$ & 120 & 1 & 3 \\
\hline 3. & Hasma Sapati & $P$ & 90 & 1 & 2 \\
\hline 4. & Jasmia Anemong & $P$ & 100 & 1 & 3 \\
\hline 5. & Siti Takasensengan & $P$ & 150 & 1 & 3 \\
\hline 6. & Amelia Tumimor & $P$ & 100 & 1 & 3 \\
\hline 7. & Rabiah Pakaya & $P$ & 120 & 1 & 3 \\
\hline 8. & Maya Lakaata & $P$ & 150 & 1 & 4 \\
\hline 9. & Hajira Harun & $P$ & 130 & 1 & 3 \\
\hline 10. & Nata Lakaata & $P$ & 100 & 1 & 3 \\
\hline 11. & Marwiah Lahadji & $P$ & 200 & 1 & 4 \\
\hline 12. & Salma pakaya & $P$ & 100 & 1 & 3 \\
\hline 13. & Fatima Lahadji & $P$ & 150 & 1 & 4 \\
\hline 14. & Amina & $P$ & 80 & 1 & 2 \\
\hline 15. & Oda Lakaata & $P$ & 90 & 1 & 2 \\
\hline 16. & Saira Harun & $P$ & 100 & 1 & 3 \\
\hline
\end{tabular}

Sumber : Data Primer, 2017 
Jika ikan masuk sebanyak 80$100 \mathrm{~kg}$ untuk proses produksi dalam sehari, tenaga kerja yang dibutuhkan 2-3 Orang, apabila produksi bahan baku 120 $\mathrm{kg}$, tenaga kerja yang dibutuhkan 3-4 orang. Tenaga kerja disesuaikan dengan banyaknya ikan yang akan diproduksi $1 \mathrm{x}$ dalam sehari.

\section{Curahan Waktu Kerja Perempuan}

Curahan kerja merupakan jerih payah yang dilaksanakan seseorang untuk mencapai suatu tujuan yang bersifat ekonomi. Dalam penelaahan curahan jam kerja laki-laki dan perempuan dalam pekerjaan rumah tangga menunjukkan secara nyata bahwa perempuan mempunyai curahan waktu yang lebih besar dalam pencarian nafkah seperti bidang industri kecil, dan industri besar dibandingkan dengan lakilaki. Curahan waktu kerja merupakan bentuk dari suatu tindakan yang dilakukan oleh seseorang karena ada motivasi dalam dirinya. Dimana motivasi yang ada dalam diri seseorang ini akan menyebabkan orang tersebut melakukan suatu tindakan yang berupa kerja,

Sugiyono (2010), curahan waktu kerja perempuan dapat dibagi menjadi dua pola, yaitu pola pekerjaan rumah tangga dan pola pencari nafkah. Dari hasil wawancara yang telah dilakukan dengan kelompok usaha pengolahan ikan cakalang Asap di Kampung Loyang Kelurahan Girian Atas Kota Bitung, disimpulkan bahwa pekerjaan perempuan pengolah ikan cakalang asap mempunyai dua pekerjaan yaitu sebagai pekerja rumah tangga dan pekerja yang menghasilkan pendapatan. Curahan waktu kerja perempuan dapat dilihat pada tabel berikut.

Tabel. Curahan Waktu Kerja Perempuan

\begin{tabular}{|c|c|c|c|c|}
\hline $\begin{array}{c}\text { Jumlah } \\
\text { Responden } \\
\text { (Orang) }\end{array}$ & $\begin{array}{c}\text { Curahan Waktu } \\
\text { Kerja di Rumah } \\
\text { (Jam) }\end{array}$ & $\begin{array}{c}\text { Curahan Waktu } \\
\text { Kerja di Ustafu } \\
\text { (Jam) }\end{array}$ & $\begin{array}{c}\text { Presentase } \\
\text { Waktu di Rumah } \\
(\%)\end{array}$ & $\begin{array}{c}\text { Presentase Waktu di } \\
\text { Ustafu } \\
\text { (\%) }\end{array}$ \\
\hline 3 & $8-9$ & $3-4$ & 75 & 25 \\
\hline 8 & $6-7$ & $5-6$ & 58 & 42 \\
\hline 5 & $>6$ & $>6$ & 50 & 50 \\
\hline
\end{tabular}

Sumber : Data Primer, 2017

Berdasarkan tabel di atas curahan waktu kerja perempuan yang menggunakan waktu di rumah dengan presentasi $75 \%$ dan memanfaatkan waktu di tempat usaha pengolahan ikan asap dengan presentasi waktu 25\% ada 3 orang. Yang menggunakan waktu kerja dirumah dengan presentasi $58 \%$ dan waktu kerja di tempat pengolahan ikan dengan presentasi waktu $42 \%$ ada 8 Orang. Sedangkan 5 orang menggunakan waktu kerja dirumah dan di tempat pengolahan ikan $50 \%$.

\section{Cara Pengupahan}

Pekerjaan yang dilakukan oleh tenaga kerja dikoodinir oleh ketua kelompok usaha ikan cakalang asap, tenaga kerja ini sudah disesuaikan dengan ketrampilan dan pengalaman erja yang dimiliki mereka,sehingga semua pekerjaan dapat dilakukan dengan baik, dan dapat menghasilkan produk sesuai dengan apa yang diharapkan. Adapun pengupahan tenaga kerja dalam usaha pengolahan ikan cakalang asap di Kelurahan Girian Atas Kota Bitung dapat dilihat pada tabel berikut. 
Tabel. Cara Pengupahan Tenaga Kerja

\begin{tabular}{|c|c|c|c|c|c|c|}
\hline No & Responden & $\begin{array}{c}\text { Jumlah } \\
\text { Bahan } \\
\text { Baku } \\
\mathbf{( K g )}\end{array}$ & $\begin{array}{c}\text { Jumlah Proses } \\
\text { Pengolahan } \\
\text { (Per Hari) }\end{array}$ & $\begin{array}{c}\text { Jumlah } \\
\text { Tenaga } \\
\text { Kerja } \\
\text { (Orang) }\end{array}$ & $\begin{array}{c}\text { Waktu } \\
\text { Kegiatan } \\
\text { (Jam) }\end{array}$ & $\begin{array}{c}\text { Upah yang } \\
\text { diperoleh } \\
\text { (Rp/hari) }\end{array}$ \\
\hline 1. & 14 & 80 & $1 \times$ Produksi & 2 & 9 & 100.000 \\
\hline 2. & 3,15 & 90 & $1 \times$ Produksi & 2 & 9 & 100.000 \\
\hline 3. & $1,4,6,10,12,16$ & 100 & $1 \times$ Produksi & 3 & 9 & 100.000 \\
\hline 4. & 2,7 & 120 & 1 x Produksi & 3 & 9 & 100.000 \\
\hline 5. & 9 & 130 & $1 \times$ Produksi & 3 & 9 & 100.000 \\
\hline 6. & $5,8,13$ & 150 & $1 \times$ Produksi & 4 & 9 & 100.000 \\
\hline 7. & 11 & 200 & $1 \times$ Produksi & 4 & 9 & 100.000 \\
\hline
\end{tabular}

Sumber : Data Primer, 2017

Berdasarkan Tabel di atas, upah yang didapatkan dalam $1 \times$ produksi adalah Rp. 100.000. Pengupahan disesuaikan dengan tenaga kerja dalam sehari, dimana upah akan diperoleh lebih banyak jika tenaga kerja yang diperlukan lebih sedikit. Hasil wawancara dengan para tenaga kerja, mereka sangat puas dengan sistem pengupahan yang berlaku.

\section{KESIMPULAN}

Berdasarkan hasil penelitian kelompok usaha pengolahan ikan cakalang asap di kampung Loyang, Kelurahan Girian Atas, Kota Bitung dapat disimpulkan sebagi berikut:

1. Kota Bitung menjadi kawasan yang sangat potensi untuk dikembangkan usaha perikanan tangkap, atas dasar itu pula Kota Bitung dikenal sebagai Kota Cakalang. Besarnya potensi sumberdaya ikan cakalang di Kota Bitung menyebabkan tingginya minat masyarakat untuk mengolah ikan, salah satunya pegolahan ikan cakalang asap atau yang dalam bahasa lokalnya dikenal dengan istilah cakalang fufu. Kota Bitung terdiri dari 8 kecamatan dan 69 kelurahan, salah satunya kelurahan girian atas, beberapa masyarakatnya memiliki pekerjaan yaitu berwirausaha. Kegiatan usahanya adalah memproduksi ikan cakalang asap. Usaha ini dilakukan untuk mengembangkan proses pengolahan ikan cakalang asap sehingga dapat menambah pendapatan daerah, memenuhi kebutuhan keluarga, dan menciptakan lapangan kerja tambahan bagi masyarakat sekitar.

2. Hasil menunjukan bahwa usaha ikan cakalang asap di kampung Loyang, Kelurahan Girian Atas, Kota Bitung masih dalam tahap "home Industry" atau industri rumah tangga. Perempuan dalam kelompok usaha pengolahan ikan cakalang asap mempunyai peranan penting, mulai dari proses ketersediaan bahan baku, penyediaan peralatan dan bahan pengolahan, pencucian, pembelahan, pemasangan pada bambu (dijepit), proses pengasapan sampai, dan pemasaran hasil pengolahan ikan cakalang asap, melibatkan peran perempuan. Proses pengolahan ikan cakalang asap dilakukan 20 kali produksi dalam sebulan, dalam $1 \mathrm{x}$ produksi apabila bahan baku ikan 80-200 Kg, tenaga kerja yang dibutuhkan 2-4 orang. Apabila ikan sebanyak 100 ekor setelah diolah 
akan menjadi 200 jepit. Dari hasil wawancara, curahan waktu kerja perempuan di tempat pengolahan ikan cakalang asap kampung Loyang, Kelurahan Girian Atas, Kota Bitung adalah 3-4 jam berjumlah 3 orang, 5-6 jam berjumlah 8 orang dan $>6$ berjumlah 5 orang. Pengupahan disesuaikan dengan tenaga kerja dalam sehari yaitu.

\section{DAFTAR PUSTAKA}

Adawyah R., 2007. Pengolahan dan Pengawetan Pangan.Jakarta:Bumi Aksara

Dinas Kelautan dan Perikanan. 2015 Data Produksi Perikanan Tangkap di Kota Bitung.Bitung

Fathoni, 2006. Metodologi Penelitian dan Teknik Penyusunan Skripsi. Rineke Cipta. Jakarta.
Harijani, D.R., 2001. Etos Kerja Perempuan Desa, Yogyakarta, Philoshophi Press

Hikmat, H. 2004. Strategi Pengembangan Masyarakat. Humaniora, Bandung.

Nawawi. H., 2003. Manajemen Sumberdaya Manusia Untuk Bisnis Yang Komptitif, Gadjah Mada University Press, Yogyakarta.

Puspitawati H., 2009. Konsep dan Teori Gender [diktat]. Bogor : Departemen IImu Keluarga dan Konsumen, Fakultas Ekologi Manusia. Institut Pertanian Bogor.

Sutedi, 2009 Penelitian Pendidikan Bahasa Jepang. Bandung: Humaniora Utama Press.

Supardi. M. D., 2006 Metode Penelitian Mataram: Yayasan Cerdas Press.

Sugiyono, 2010. Metode Penelitian Kuantitatif Kualitatif \& RND. Bandung : Alfabeta. 